\title{
BRANCA DIAS, LEGENDÁRIA VÍTIMA DA INQUISIÇÃO.
}

\section{GERALDO JOFFILY}

Uma das mais pungentes tradições populares da várzea canavieira na antiga Capitania de Pernambuco nos dá notícia do sacrifício de uma jovem senhora de engenho, chamada Branca Dias, dona de muitas terras e cabedais, de todos respeitada pelo seu poder, que de repente se viu chamada a comparecer perante a inquisição do Tribunal do Santo Ofício de Lisboa, guardando-se de bôca em bôca, a memória de que teria sido queimada como feiticeira ou herege, sendo desmanchadas as moendas e caldeirões de sua fábrica de açúcar e derrubadas as paredes do casarão onde habitava, na ânsia de achar os dobrões de ouro e pratarias escondidos pela mártir judia.

Este fantasma, bem desenhado por uma tradição popular incontestável, sempre preocupou os melhores historiadores nordestinos, que debalde cataram nos arquivos daqui e de lá alguma referência melhor detalhada.

Em caderno recentemente publicado com o título de Um Cronista do Sertão, tive oportunidade de ajuntar, entre outros, um artigo de Irenêo Joffily (o historiador) sôbre a lenda desta Branca Dias, onde se referia a um outro trabalho seu, publicado no "Comércio de Pernambuco" de 22 de março de 1897, que debalde procurei nas bibliotecas do Recife.

Só agora pude ter o indicado artigo, reaparecendo, com agradável surprêsa, uma curiosa indagação dêste singular cronista e historiador paraibano, Irenêo Joffily, e a resposta de Pereira da Costa, o mais sério pesquisador da história de Pernambuco:

Não é o local do nascimento desta Branca Dias o que maịs nos interessa, e sim, e muito particularmente, o reflexo dessa imagem na "tradição popular" confirmada por ambos. Tenha-se em vista que durante mais de dois séculos foi o Nordeste Brasileiro atormentado pelos tribunais do Santo Ofício, devendo-se considerar a influência residual, indelével, dêsses acontecimentos, divulgados, cautelosamente, com narrativas sôbre a liturgia macabra dêstes autos-de-fé, onde 
apareciam irmandades encapuçadas cantando misereres, enquanto os impenitentes eram amarrados sôbre as fogueiras, vestidos em sambenitos de baeta vermelha.

Mesmo antes de 1600 , o terrível dedo da Inquisição já estava apontado para as capitanias açucareiras, onde se abrigavam numerosos marranos, também ocupados com o tráfico de escravos. Como anotam as valiosas Datas e Notas de Irineu Pinto (p. 131):

"em outubro de 1731, é queimada em Lisboa pelo Tribunal do Santo Ofício D. Guiomar Nunes, cristão nova, de trinta e sete anos de idade, casada com Francisco Pereira, filha de Pernambuco e moradora no engenho Sto. André, desta capitania, por convicta, negativa e pertinaz".

Daí a oportuna indagação de Irenêo Joffily:

"Por que entre tantas vítimas partidas daqui e da vizinha capitania de Pernambuco para os cárceres da Inquisição, a memória popular só conservou o nome de Branca Dias?".

Teria influído a inequívoca sonoridade destas palavras: branca dias, como fator psicológico? Pergunto eu: reafirmando a importância de que se tenha sempre em vista não apenas a identificação retrospectiva, mas, também, a própria lenda, em si e por si, como um fenômeno, mostrando a sombra dêstes acontecimentos no espírito popular daquela época.

Vejamos as breves considerações dos indicados mestres, que muito embora não tragam novidade, poderão servir de ilustração para outras reapreciações:

Branca Dias - A legenda paraibana tem conservado êste nome através das idades, como a principal vítima da Inquisição nesta antiga capitania, nos princípios do século dezassete.

"A tradição nos diz que era senhora de alta posição na sociedade colonial pela ilustre família a que pertencia e pela opulência em que vivia no seu engenho próximo à cidade da Paraíba, o que, contrastando com o seu miserando fim, resultado da perseguição que the moveu o terrível Tribunal, influiu de tal modo na imaginação popular, que o seu nome tem atravessado três séculos.

Mas qual era a família de Branca Dias?

Seguiria ela a religião judaica?

Qual o engenho que the pertencia?

São perguntas que acudirão à mente do leitor e d̀s quais não posso responder cabalmente.

Entretanto a curiosidade e interêsse que me desperta 0 assunto, obriga-me a encará-lo com o fim de convidar a quem quer que o possa esclarecer, a vir a público. 
Sempre entendi e entendo que o fato é histórico, muito embora adornado pela legenda através dos tempos. Desde tenra idade que ouço falar nessa célebre mulher e tão célebre que o seu ruidoso processo e deplorável fim nas fogueiras do Santo Ofício, deu lugar que os paraibanos seus patrícios, ficassem suspeitos de judaismo pelos habitantes das capitanias visinhas.

Nos tempos escolares quando estudava na cidade do Recife, era freqüente a troça aos estudantes da Paraíba feita pelos seus colegas de outras províncias: - paraibano não come toucinho, é descendente de judeu, etc.

Procurei então na história o esclarecimento do fato e nada encontrei. Apenas Varnhagen em sua - História Geral do Brasil - diz que a Paraíba e o Rio de Janeiro foram as capitanias que mais sofreram da Inquisição.

Muitos anos depois, lendo os numerosos e valiosíssimos documentos tirados dos arquivos públicos da Holanda pelo ilustrado Dr. José Higino quando ali esteve em comissão do Instituto Arqueológico de Pernambuco, deparei, em um dêles, com o nome de - Príncipe da Paraíba - dado a um opulento judeu aí morador.

Tudo isso aguçou a minha curiosidade sem concorrer para o esclarecimento que procurava. Compreendi então que sòmente em Lisboa, sede que foi do tenebroso Tribunal e onde deve existir o seu arquivo, poderia vir à luz. Fiquei pois, sem esperança pela impossibilidade de lá ir.

Mas veio-me ultimamente às mãos um número da revista do Instituto Arqueológico de Pernambuco, onde li um interessante escrito do seu ilustre consócio Dr. Francisco Augusto Pereira da Costa, no qual mencionando os nomes de tôdas as pessoas prêsas em Pernambuco de ordem da Inquisição, fala de uma Branca Dias, mãe de uma das vítimas.

Julguei então que êle poderia dar-me esclarecimento sôbre êsse obscuro ponto da história paraibana e lhe dirigi a respeito uma carta.

Não se fêz esperar a resposta do ilustrado Dr. Pereira da Costa, a qual a devida vênia, transcrevo em seguida:

"O fato que refiro no meu trabalino, da prisão de Brites Fernandes, fllha de Dlogo Fernandes e de Branca Dias, que teve lugar em Pernambuco, em 1601, é referido por Borges da Fonseca na sua Noblliarquia, mas com relação especial a Branca Dias, o que set, consta de uma tradiçáo muito vulgar entre nós e já com foros de cldade por mals de uma publicação e eu mesmo já utllizel dela em um livrinho que publiquel em 1884 o - Mosalco Pernambucano - desta forma:

"Riacho da Prata - Branca Dias, rica senhora de engenho em Apipucos, tendo sido denunciada ao Tribunal do Santo Ofício por crime de judalsmo, na ocasiano de the ser intimada a ordem de prisano, arremessou ao açude que por all corria, tôđa a sua balxela e mais objetos de prata que possuia. Eis, pois, donde vem o nome que se dá a êsse riacho. 


\begin{abstract}
"Branca Dias seguiu para Portugal e lá morreu nas fogueiras da Inquisiçá, de cujo auto de fé existe um quadro no Convento de Sáo Francisco na cidade da Paraíba.

"Eis a lenda. Será essa Branca Diàs, a mulher de Diogo Fernandes e mäe de Brites Fernandes, a primeira vitima da Inquisição em Pernambuco? E' bem provével.

"Diogo Fernandes era feitor do engenho Camaragibe e talvez fazendo algum pecúlio, comprasse as terras contíguas, que pertenciam a um dos engenhos Camaragibe ou Apipucos no centro dos quals esta encravada a terra em questão e aí levantaisse o seu engenho que é, sem dúvida, o dos Dois Irmäos, hoje extinto, junto ao riacho da Prata, cujas éguas moiam as suas canas. E note-se que a lenda náo diz que Branca Dias era senhora do engenho Pipucos, que ficava a pouca distância onde se levanta a povoạçáo do mesmo nome, mas sim que era senhora em pipucos, - que robustece a minha crença.

"Eis o que posso adlantar a questão".
\end{abstract}

Esta interessante carta veio complicar a questão, porque desloca o fato ou lenda da Paraíba para Pernambuco ou antes cria mais uma Branca Dias, para êste Estado.

Mas o tópico em que diz existir no Convento de São Francisco da Paraíba, um quadro do auto de fé em que foi vítima Branca Dias, é da maior importância e vem robustecer a lenda paraibana.

Verificada a existência do dito quadro, êle, por si só constitui prova robusta de que a lenda assenta sob um fato histórico e ainda mas, que é de presumir ou antes é provável que a vítima era da Paraíba e não de Pernambuco. O que, a não ser assim, o quadro deveria estar em qualquer um dos conventos da mesma ordem em Pernambuco e não em outra capitania.

Além disso, desde que Borges da Fonseca citado pelo Dr. Pereira da Costa, não menciona Branca Dias como uma das vítimas da Inquisição em Pernambuco, não parece ter o menor fundamento a lenda pernambucana que não é mais, talvez, do que um reflexo da outra.

Diz-se que uma das mais distintas famílias da Paraíba é descendente de Branca Dias. Será exato? A luz do nosso século, é uma ascendência que não envergonha, é antes muito honrosa.

Se o fato não é da máxima importância histórica, é contudo muito curioso e merece que os estudiosos e os mais entendidos das tradiçōes históricas ministrem esclarecimentos que tornem bem autenticados.

Campina, junho de 1896. as. Irenêo Joffily".

$E^{\prime} \cdot o$ que consta desta bem intencionada crônica, recapitulando um episódio cercado de imaginação, mas tão plástico (por solidariedade, talvez) que me dispus reviver, tendo em vista mais o reflexo da imagem do que a positivação. 